\title{
An observational study of simultaneous pulse oximetry and arterial oxygen saturation readings in intensive care unit/high dependency unit in COVID-19 patients
}

\author{
Nadia Rose', Ramya B Sriram², Karthik GS ${ }^{3}$, Sowmya $\mathbf{M J}^{4}$, Sudheer $\mathbf{R}^{\mathbf{5}}$ \\ ${ }^{1}$ Assistant Professor, ${ }^{2}$ Post Graduate Resident, ${ }^{3,4,5}$ Professor, Department of Anaesthesiology, Rajarajeswari Medical \\ College and Hospital, Bengaluru, Karnataka, India
}

Background: The coronavirus-2019 (COVID-19) pandemic has increased the use of pulse oximeters worldwide. It has become an inevitable tool in the monitoring of the disease. However, the accuracy of pulse oximeters in COVID-19 has not been established. Aims and Objectives: The aims of the study were to examine the relationship between oxygen saturation as measured by pulse oximeter $\left(\mathrm{SpO}_{2}\right)$ and oxygen saturation measured by arterial blood gas analysis $\left(\mathrm{SaO}_{2}\right)$ measurements in COVID-19 patients admitted to the intensive care unit (ICU)/high dependency unit (HDU) and to assess the ability of $\mathrm{SpO}_{2}$ readings to detect low $\mathrm{SaO}_{2}$ and low oxygen tension in COVID-19 patients. Materials and Methods: This prospective observational study was conducted in the COVID-19 ICU and high dependency unit of a tertiary care hospital in Bengaluru, India. All patients admitted with confirmed COVID-19, meeting the eligibility criteria, were included in the study. We assessed bias and limits of agreement between paired samples of oxygen saturation from pulse oximetry $\left(\mathrm{SpO}_{2}\right)$ and arterial oxygen saturation from blood gas analysis $\left(\mathrm{SaO}_{2}\right)$. Results: The sample mean difference $\mathrm{SpO}_{2}-\mathrm{SaO}_{2}$ is $-0.86 \%$ (bias) and the $95 \%$ confidence interval for the mean difference was -1.67 and -0.04 . The lower limit of agreement was -7.32 with a $95 \%$ confidence interval $(-8.74,-5.91)$. The upper limit of agreement was 5.61 with a $95 \%$ confidence interval of 4.19 and 7.02. Conclusion: $\mathrm{SpO}_{2}$ values are not completely dependable in estimating $\mathrm{SaO}_{2}$ in COVID-19 patients in ICU/HDU; therefore, arterial blood gas analysis measurement of oxygen saturation has to be done depending on the clinical scenario CTRI (CTRI/2020/11/029035).

Key words: COVID-19; Oxygen saturation from $\mathrm{ABG}$; $\mathrm{SpO}_{2}$

\section{INTRODUCTION}

The ongoing coronavirus pandemic has caused pain and suffering all across the globe. Although huge leaps have been made in the fields of medicine in the past century, the pandemic has proven to be a great challenge to humankind. The understanding of the virus and its mechanism is not complete and still eludes scientists. The world is struggling and to date, no drugs have been proven to be curative and no vaccine has been found to have $100 \%$ efficacy.

\section{Access this article online}

Website:

http://nepjol.info/index.php/AJMS DOI: 10.3126/ajms.v13i3.41218

E-ISSN: 2091-0576

P-ISSN: 2467-9100

Copyright (c) 2022 Asian Journal of Medical Sciences

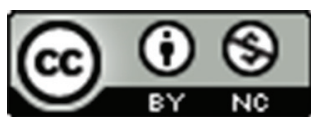

This work is licensed under a Creative Commons Attribution-NonCommercial 4.0 International License. 
in red band. Pulse oximeter works by estimating oxygen saturation from pulse oximetry $\left(\mathrm{SpO}_{2}\right)$ from this differential absorption of red $(660 \mathrm{~nm})$ and infrared $(940 \mathrm{~nm})$ light. $^{1}$

Some coronavirus-2019 (COVID-19)-positive patients have profound hypoxemia, but respiratory distress shown by them may not correspond to their oxygen levels, that is, they might not be exhibiting signs of distress as expected. ${ }^{2}$ This peculiar feature of COVID-19 patients can make timely referral to the intensive care units (ICUs) difficult. Knowing the relationship between $\mathrm{SpO}_{2}$, arterial oxygen saturation from blood gas analysis $\left(\mathrm{SaO}_{2}\right)$, and arterial oxygen tension $\left(\mathrm{PaO}_{2}\right)$ will greatly help in timely oxygen therapy for COVID-19 patients.

Hence, we conducted this observational study in COVID19-positive patients admitted to intensive care and high dependency units (HDUs) due to COVID-related complications. Ebmeier et al., ${ }^{3}$ have shown that there could be clinically important difference in agreement between $\mathrm{SpO}_{2}$ and $\mathrm{SaO}_{2}$ readings in non-COVID patients in ICU. Some studies have shown that $\mathrm{SpO}_{2}$ can be approximated to the blood oxygen saturation levels obtained from arterial blood gas analysis but few other studies have shown to have results that are contradictory.-6 Philip et al., in their study, noted that the agreement between $\mathrm{SpO}_{2}$ and $\mathrm{SaO}_{2}$ was limited to a small degree in COVID-19 patients. $^{7}$

\section{Aims and objectives}

The aims of our study were to examine the relationship between oxygen saturation as measured by pulse oximeter $\left(\mathrm{SpO}_{2}\right)$ and oxygen saturation measured by arterial blood gas analysis $\left(\mathrm{SaO}_{2}\right)$ measurements in COVID-19 patients admitted to ICU/HDU and to assess the ability of $\mathrm{SpO}_{2}$ readings to detect low $\mathrm{SaO}_{2}$ and low oxygen tension $\left(\mathrm{PaO}_{2}\right)^{2}$ in COVID-19 patients.

\section{MATERIALS AND METHODS}

This is a single-center prospective observational crosssectional study in the ICU and HDU of a tertiary care hospital during the COVID-19 pandemic from November 2020 to February 2021. Our hospital was a major hospital dedicated to COVID patients during the first wave of the pandemic in India. The Institutional Ethics Committee approval was obtained and study registered in CTRI (CTRI/2020/11/029035).

Criteria for admission of reverse transcription-polymerase chain reaction confirmed COVID-19-positive patients to the ICU included: Saturation $<90 \%$ in room air, adult respiratory distress syndrome, sepsis, or comorbid conditions with concern for clinical deterioration. Admission to HDU: Saturation $<94 \%$ in room air
(90-94\%), respiratory rate more than $24 /$ min, tachycardia more than $120 / \mathrm{min}$, or any abnormal laboratory values.

\section{Inclusion criteria}

COVID-19-positive patients of age more than or equal to 18 years and $\leq 80$ years admitted to ICU/HDU.

\section{Exclusion criteria}

Patients aged $<18$ years and $>80$ years, diagnosis of methemoglobinemia, smokers, and patients with nail polish were excluded from the study.

Informed consent was obtained for including patient's data in the study. Demographic data and comorbid conditions of all patients were noted. All patients admitted to the units were given routine monitoring of vitals and arterial blood gas sampling was done when clinically indicated as part of routine clinical management of COVID-19 and any associated disease. No investigations were done solely for the purpose of the study. Paired recording of $\mathrm{SpO}_{2}$ and $\mathrm{SaO}_{2}$ was done simultaneously. ${ }^{3}$ The $\mathrm{SpO}_{2}$ value on the monitor at the time when the blood was seen to enter the ABG collection syringe was noted for simultaneous reading and the sample was immediately analyzed using ABL80 FLEX blood gas analyzer, after removing air bubbles. The blood gas analyzer was properly calibrated. The $\mathrm{SpO}_{2}$ recordings were done using Skanray Star 65 monitor with Nellcor Nell $1 \mathrm{SpO}_{2}$ monitor and Mindray Mec 2000 monitor with adult $\mathrm{SpO}_{2}$ sensor probes. The monitors were calibrated by the biomedical department of our institution. All $\mathrm{SpO}_{2}$ values were taken using finger probes. Finger probe was placed in the opposite hand as that of arterial blood gas sampling. The measurements were taken 3-4 h after admission to the unit. Local factors influencing pulse oximeter readings and use of vasoactive drugs were noted. Acute Physiology and Chronic Health Evaluation II score ${ }^{8}$ was calculated within the first $24 \mathrm{~h}$ of admission to the unit. Type of oxygen therapy for COVID-19 respiratory failure was noted along with $\mathrm{FiO}_{2}$ at the time of sampling.

\section{Statistical analysis}

All data collected were entered into Microsoft Office Excel worksheet. Quantitative data were expressed as mean and standard deviation. Qualitative data were expressed as proportions. Bland-Altman method ${ }^{9}$ was used for assessing agreement between $\mathrm{SaO}_{2}$ and $\mathrm{SpO}_{2}$. Statistical program $\mathrm{R}$ was used for the statistical analysis.

\section{RESULTS}

Sixty-five paired measurements were taken from 65 patients admitted to the ICU and HDU. Thirty-nine patients were from ICU and rest from HDU. Table 1 shows the characteristics of patients. Comorbid conditions such as 
cardiovascular disease and diabetes mellitus were noted but not used for further analysis. Modes of oxygen therapy used for COVID-19 pneumonia were included in the study. Table 1 shows patient characteristics. Table 2 shows the values obtained from arterial blood gas analysis and oxygen saturation from pulse oximeter.

\begin{tabular}{lc}
\multicolumn{2}{l}{ Table 1: Characteristics of patients } \\
\hline Age (years), mean (SD) & $57.72(15.20)$ \\
Sex, $n(\%)$ & Female $19(29.23 \%)$ \\
APACHE II score, mean (SD) & $12.35(5.35)$ \\
Vasopressors/Inotropes, $n(\%)$ & $7(10.7 \%)$ \\
Comorbid conditions, $n(\%)$ & \\
Cardiovascular disease & $14(21.5 \%)$ \\
Diabetes mellitus & $10(15.4 \%)$ \\
Chronic kidney disease & $3(4.6 \%)$ \\
Modes of oxygen therapy, $n(\%)$ & \\
NIV ${ }^{*}$ & $21(32.31 \%)$ \\
Intubated & $3(4.62 \%)$ \\
NRBM+ & $33(50.77 \%)$ \\
HFNO++ & $2(3.08 \%)$ \\
Face mask & $6(9.23 \%)$ \\
\hline
\end{tabular}

*NIV: Non-invasive ventilation, ${ }^{+}$NRBM: Non-rebreather mask, ${ }^{+}{ }^{+} \mathrm{HFNO}$ : High-flow nasal oxygen, APACHE: Acute Physiology and Chronic Health Evaluation, SD: Standard deviation

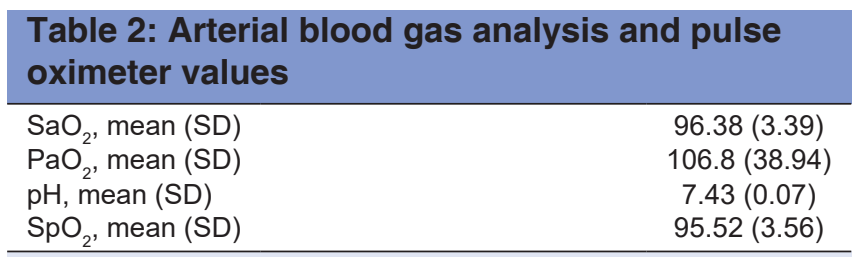

$\mathrm{SD}$ : Standard deviation, $\mathrm{SaO}_{2}$ : Arterial oxygen saturation, $\mathrm{PaO}_{2}$ : Arterial oxygen tension

Relation between $\mathrm{SpO}_{2}$ and $\mathrm{SaO}_{2}$

The purple segment gives the $95 \%$ confidence interval for the bias with the middle dashed line being the mean bias, the pink segment gives 95\% confidence interval for the lower limit of agreement, and green segment gives the $95 \%$ confidence interval for the upper limit of agreement.

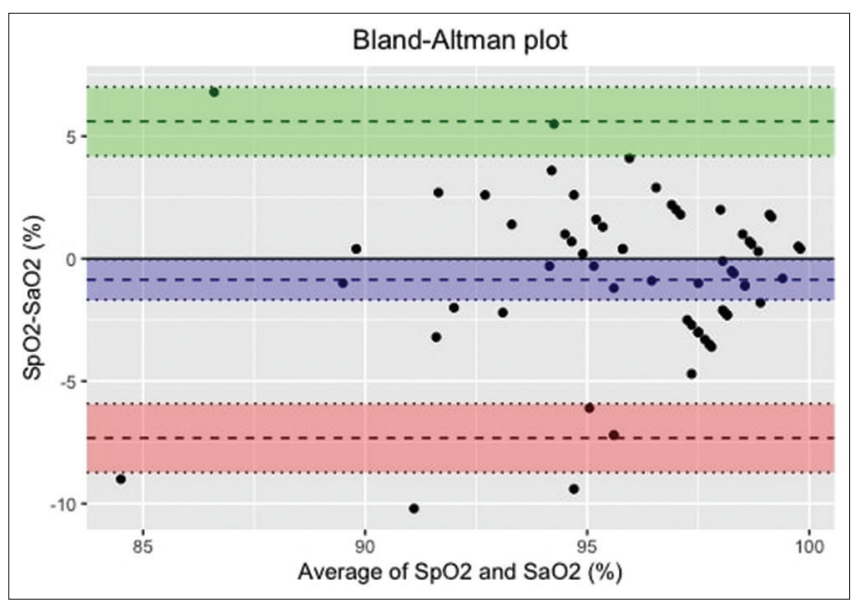

Figure 1: Bland-Altman plot
Figure 1 shows the Bland-Altman plot for graphical representation of the relationship between $\mathrm{SpO}_{2}$ and $\mathrm{SaO}_{2}$. Bias and limits of agreement were calculated. The sample mean difference $\mathrm{SpO}_{2}-\mathrm{SaO}_{2}$ was $0.86 \%$ (bias) and the $95 \%$ confidence interval for the mean difference is -1.67 and -0.04 . This indicates that the mean of $\mathrm{SpO}_{2}$ is less than the mean of $\mathrm{SaO}_{2}$ for all COVID-19 patients in the world. The lower limit of agreement was -7.32 with a $95 \%$ confidence interval $(-8.74,-5.91)$. The upper limit of agreement was 5.61 with a $95 \%$ confidence interval of 4.19 and 7.02 .

We built a linear model to measure the relationship between $\mathrm{SpO}_{2}-\mathrm{SaO}_{2}$ and mean arterial pressure (MAP) at the time of sampling. The estimated coefficient of MAP was 0.044 with a $\mathrm{P}=0.246$. The $\mathrm{R}^{2}$ coefficient was only 0.021 which indicated that MAP has no significant association between the differences $\mathrm{SpO}_{2}$ and $\mathrm{SaO}_{2}$. We next tested the relationship with hematocrit values which also showed no significant association, estimate was 0.02 , and $\mathrm{P}=0.808$ and $\mathrm{R}^{2}$ was 0.00095 .

Ability of pulse oximeter to detect hypoxemia-SpO $\leq 92 \%$ had a specificity $87 \%$ and sensitivity $100 \%$ to detect $\mathrm{SaO}_{2}$ of $90 \%$ or less. The specificity was $84 \%$ and sensitivity was $50 \%$ for $\mathrm{SpO}_{2} \leq 92 \%$ to detect $\mathrm{PaO}_{2} \leq 60 \mathrm{mmHg}$. $\mathrm{SpO}_{2}$ $\leq 90 \%$ showed specificity $95 \%$ and sensitivity $75 \%$ to detect a $\mathrm{SaO}_{2}$ of $90 \%$ or less. $\mathrm{SpO}_{2} \leq 90 \%$ had a specificity $93 \%$ and sensitivity $50 \%$ to detect $\mathrm{PaO}_{2} \leq 60 \mathrm{mmHg}$.

\section{DISCUSSION}

Pulse oximeters are being widely used during the pandemic but evidence regarding the precision of pulse oximeter in COVID-19 patients is limited. There are not many studies addressing the same. Our findings from these 65 COVID-19-positive patients admitted to ICU and HDU show that the limits of agreement are suboptimal than other studies although the bias is $-0.86 \%$. The negative bias shows that $\mathrm{SpO}_{2}$ underestimates $\mathrm{SaO}_{2}$. Thirty-six out of 65 patients had their $\mathrm{SpO}_{2}$ values $<\mathrm{SaO}_{2}$ and six patients showed more than $5 \%$ difference between $\mathrm{SpO}_{2}$ and $\mathrm{SaO}_{2}$ in our study. Some studies have shown that $\mathrm{SpO}_{2}$ overestimates $\mathrm{SaO}_{2}$ while some have shown opposite results. Philip et al., ${ }^{7}$ in their study on 30 patients recovering from severe COVID-19 infection, noted suboptimal levels of agreement between $\mathrm{SpO}_{2}$ and $\mathrm{SaO}_{2}$ and a bias of $0.4 \%$. Van de Louw et al., ${ }^{10}$ have shown that $\mathrm{SpO}_{2}$ underestimates $\mathrm{SaO}_{2}$ at low oxygen saturation in non-COVID patients. They also noted a great difference between $\mathrm{SpO}_{2}$ and $\mathrm{SaO}_{2}$ in a study on 102 non-COVID patients in ICU. Seguin et al., ${ }^{11}$ in their study in non-COVID patients, noted that $\mathrm{SpO}_{2}$ overestimated $\mathrm{SaO}_{2}$ and the limits of agreements were also large. 
Wilson-Baig et al., ${ }^{12}$ noted that $\mathrm{SpO}_{2}$ underestimated arterial blood gas saturation measurements in COVID-19 patients $(\mathrm{n}=17)$, the probable reasons cited for this being tissue hypoxia, different spectral properties of $\mathrm{d}$-dimer and ferritin, formation of complexes between the coronavirus and hemoglobin and proposed that the situation of "happy hypoxemia" noted in COVID-19 patients might be due to these reasons. The limits of agreement values of our study indicate that caution should be advised when oxygen therapy is titrated solely based on $\mathrm{SpO}_{2}$ measurements.

The pulse oximeter value of $90 \%$ or less had poor sensitivity in detecting low $\mathrm{PaO}_{2}(\leq 60 \mathrm{mmHg})$ and $\mathrm{SaO}_{2}$ of $90 \%$ or less in our study. This shows poor diagnostic accuracy of $\mathrm{SpO}_{2}$ readings in estimating hypoxemia. Sensitivity of $\mathrm{SpO}_{2}<90 \%$ to detect a $\mathrm{PaO}_{2}$ of $<60 \mathrm{mmHg}$ in non-COVID patients was much higher in some studies but low sensitivity has been shown in others. Pilcher et al., ${ }^{13}$ showed a sensitivity of $88.6 \%$ and specificity $95.1 \%$ for $\mathrm{SpO}_{2}<90 \%$ to detect $\mathrm{SaO}_{2}<90 \%$ and a sensitivity of $70.5 \%$ and specificity of $98.2 \%$ to detect $\mathrm{PaO}_{2}<60 \mathrm{mmHg}$ in their study on non-COVID patients.

Our study has various strengths. Single paired measurement was taken from each patient. The measurements were taken simultaneously; the arterial blood gas analysis was done immediately, so there was almost no time lag between both measurements. As the measurements were taken simultaneously, fluctuations in oxygen levels ${ }^{14}$ which could have happened over time were negated. This was useful in improving the validity and removing any bias from collecting data from the same patient by repeated measurements. ${ }^{13}$

Ethnicity and skin color ${ }^{15,16}$ could affect the agreement between $\mathrm{SpO}_{2}$ and $\mathrm{SaO}_{2}$ but all our patients were of same South Indian ethnicity. $\mathrm{SpO}_{2}$ can overestimate $\mathrm{SaO}_{2}$, especially when saturation is low in individuals who are dark skinned. ${ }^{17}$

We excluded smokers, people with methemoglobinemia, and patients with nail polish from our study thereby avoiding some factors which could potentially affect the pulse oximeter accuracy as seen in the previous studies. ${ }^{13,18,19}$ Other local factors which could affect $\mathrm{SpO}_{2}$ measurements such as poor signal and motion artifacts were not observed in any patient during measurement.

These findings are from a single hospital in a single geographical area. More extensive studies with higher sample size, different clinical situations, and with different models of pulse oximeters have to be done to extrapolate the findings to other COVID-19-positive patients during the pandemic. Different models and low-quality finger pulse oximeter probes are widely available in the market and are being used extensively as many hospitals are stretched beyond their admission capacities.

\section{Limitations of the study}

There are some limitations for the study that has to be considered. Original planned sample size using Yamane equation ${ }^{20}$ was 100 , considering 135 COVID-19 admissions as population size and degree of error 0.05 . However, the admissions of COVID-19-positive patients decreased during the study time as the first wave of the pandemic had already peaked; we were able to get data of 65 eligible patients during the study period.

Values such as ferritin and d-dimers which could have different spectral properties ${ }^{21}$ at 660 and 940 nanometers as suggested by Wilson-Baig et al., ${ }^{12}$ were not considered in this study. Studying these values in COVID-19 patients will aid in understanding the relation with $\mathrm{SpO}_{2}$ better, if any exists.

\section{CONCLUSION}

Oxygen therapy and titration are mostly guided by pulse oximeter in almost all COVID treatment centers as it is non-invasive and simple method and offers continuous monitoring. However, our study shows that $\mathrm{SpO}_{2}$ values are not completely dependable in estimating $\mathrm{SaO}_{2}$ in COVID-19 patients in ICU/HDU due to suboptimal limits of agreement. Arterial blood gas measurements have to be obtained depending on the clinical scenario of the patient.

\section{ACKNOWLEDGMENT}

Dr. Monisha, Dr. Kishore

\section{REFERENCES}

1. Dorsch JA and Dorsch SE. Understanding Anaesthesia Equipment. $5^{\text {th }}$ ed. Philadelphia, PA: Wolters Kluwer, Lippincott Williams and Wilkins; 2007.

2. Dhont S, Derom E, Van Braeckel E, Depuydt $P$ and Lambrecht BN. The pathophysiology of "happy" hypoxemia in COVID-19. Respir Res. 2020;21(1):198. https://doi.org/10.1186/s12931-020-01462-5

3. Ebmeier SJ, Barker M, Bacon M, Beasley RC, Bellomo R, Chong CK, et al. A two centre observational study of simultaneous pulse oximetry and arterial oxygen saturation recordings in intensive care unit patients. Anaesth Intensive Care. 2018;46(3):297-303.

https://doi.org/10.1177/0310057X1804600307

4. Bilan N, Behbahan AG, Abdinia B and Mahallei M. Validity of pulse oximetry in detection of hypoxaemia in children: Comparison of ear, thumb and toe probe placements. East Mediterr Health J. 2010;16(2):218-222. 
5. Nesseler N, Frénel JV, Launey $Y$, Morcet J, Mallédant $Y$ and Seguin P. Pulse oximetry and high-dose vasopressors: A comparison between forehead reflectance and finger transmission sensors. Intensive Care Med. 2012;38(10):17181722.

https://doi.org/10.1007/s00134-012-2659-0

6. Goodgame B, Zeserson E, Hess J, Daniel C, Schultz K, Hoon C, Lamb K, et al. Correlation of pulse oximetry and arterial $\mathrm{pO}_{2}$ in the undifferentiated critically ill patient. Crit Care Med. 2012;40(12):1-328.

https://doi.org/10.1097/01.ccm.0000424632.30897.65

7. Philip KE, Bennett B, Fuller S, Lonergan B, McFadyen C, Burns J, et al. Working accuracy of pulse oximetry in COVID-19 patients stepping down from intensive care: A clinical evaluation. BMJ Open Respir Res. 2020;7(1):e000778.

https://doi.org/10.1136/bmjresp-2020-000778

8. Zou X, Li S, Fang M, Hu M, Bian Y, Ling J, et al. Acute physiology and chronic health evaluation II score as a predictor of hospital mortality in patients of coronavirus disease 2019. Crit Care Med. 2020;48(8):e657-e665.

https://doi.org/10.1097/CCM.0000000000004411

9. Bland JM and Altman DG. Statistical methods for assessing agreements between two methods of clinical measurement. Lancet. 1986;1(8476):307-310.

https://doi.org/10.1016/S0140-6736(86)90837-8

10. Van de Louw A, Cracco $C$ and Cerf C. Accuracy of pulse oximetry in the intensive care unit. Intens Care Med. 2001;27(10):1606-1613.

https://doi.org/10.1007/s001340101064

11. Seguin P, Le Rouzo A, Tanguy M, Guillou YM, Feuillu A and Malledant $Y$. Evidence for the need of bedside accuracy of pulse oximetry in an intensive care unit. Crit Care Med. 2000;28(3):703-706.

https://doi.org/10.1097/00003246-200003000-00017

12. Wilson-Baig $\mathrm{N}, \mathrm{McD}$ onnell $\mathrm{T}$ and Bentley $\mathrm{A}$. Discrepancy between $\mathrm{S}_{\mathrm{p}} \mathrm{O}_{2}$ and $\mathrm{S}_{\mathrm{a}} \mathrm{O}_{2}$ in patients with COVID-19. Anaesthesia. 2021;76 (Suppl 3):6-7.

https://doi.org/10.1111/anae.15228

13. Pilcher J, Ploen L, McKinstry S, Bardsley G, Chien J, Howard L, et al. A multicentre prospective observational study comparing arterial blood gas values to those obtained by pulse oximeters used in adult patients attending Australian and New Zealand hospitals. BMC Pulm Med. 2020;20(1):7.

https://doi.org/10.1186/s12890-019-1007-3

14. Luks $A M$ and Swenson ER. Pulse oximetry for monitoring patients with COVID-19 at home. Potential pitfalls and practical guidance. Ann Am Thorac Soc. 2020;17(9):1040-1046.

https://doi.org/10.1513/AnnalsATS.202005-418FR

15. Michael W, Dickson RP, Theodore J, Steven E and Thomas S. Racial bias in pulse oximetry measurement. $\mathrm{N}$ Engl $\mathrm{J}$ Med. 2020;383(25):2477-2478.

https://doi.org/10.1056/NEJMc2029240

16. Perkins GD, McAuley DF, Giles S, Routledge $H$ and Gao F. Do changes in pulse oximeter oxygen saturation predict equivalent changes in arterial oxygen saturation? Crit Care. 2003;7(4):R67-R71.

https://doi.org/10.1186/cc233

17. Bickler PE, Feiner JR and Severinghaus JW. Effects of skin pigmentation on pulse oximeter accuracy at low saturation. Anaesthesiology. 2005;102(4):715-719.

https://doi.org/10.1097/00000542-200504000-00004

18. Pretto JJ, Roebuck T, Beckert $L$ and Hamilton G. Clinical use of pulse oximetry: Official guidelines from the thoracic society of Australia and New Zealand. Respirology. 2014;19(1):38-46. https://doi.org/10.1111/resp.12204

19. Cicek HS, Gumus S, Deniz O, Yildiz S, Açikel CH, Çakir E, et al. Effect of nail polish and henna on oxygen saturation determined by pulse oximetry in healthy young adult females. Emerg Med J. 2011;28(9):783-785.

https://doi.org/c10.1136/emj.2010.096073

20. Adam AM. Sample size determination in survey research. J Sci Res Rep. 2020;26(5):90-97. https://doi.org/10.9734/jsrr/2020/v26i530263

21. Sarikonda KV, Ribeiro RS, Herrick JL and Hoyer JD. Hemoglobin Lansing: A novel hemoglobin variant causing falsely decreased oxygen saturation by pulse oximetry. Am J Hematol. 2009;84(8):541.

https://doi.org/10.1002/ajh.21452

\footnotetext{
Authors Contribution:

NR-Conception, acquisition, analysis, interpretation of data, drafting, approval of final version, and agrees to be accountable for all aspects of work;

RBS- Acquisition, drafting, approval of final version, and agrees to be accountable for all aspects of work; KGS- Analysis, revising critically, approval of final version, and agrees to be accountable for all aspects of work; SMJ- Acquisition, interpretation of data, drafting, approval of final version, and agrees to be accountable for all aspects of work; and SR- Interpretation of data, revising critically, approval of final version, and agrees to be accountable for all aspects of work

Work attributed to:

Rajarajeshwari Medical College and Hospital, Mysore Road, Bengaluru - 560 060, Karnataka, India

Orcid ID:

Nadia Rose - https://orcid.org/0000-0002-1667-7337

Ramya B Sriram - (i) https://orcid.org/0000-0001-8337-8241

Karthik GS - (i) https://orcid.org/0000-0001-5102-1133

Sowmya MJ - it https://orcid.org/0000-0002-0962-3234

Sudheer R - (i) https://orcid.org/0000-0002-8706-7712

Source of Support: None, Conflicts of Interest: None.
} 